(1)

CrossMark

\title{
COVID-19 and pulmonary rehabilitation: preparing for phase three
}

\author{
Massimiliano Polastri (10 ${ }^{1}$, Stefano Nava ${ }^{2,3}$, Enrico Clini $\mathbb{1}^{4}$, Michele Vitacca (i) $^{5}$ \\ and Rik Gosselink (10.7
}

Affiliations: ${ }^{1}$ Medical Dept of Continuity of Care and Disability, Physical Medicine and Rehabilitation, St Orsola University Hospital, Bologna, Italy. ${ }^{2}$ Dept of Clinical, Integrated and Experimental Medicine (DIMES), University of Bologna, Bologna, Italy. ${ }^{3}$ Respiratory and Critical Care Unit, St Orsola University Hospital, Bologna, Italy. ${ }^{4}$ University Hospital of Modena Policlinico, Respiratory Diseases Unit, Dept of Medical and Surgical Sciences SMECHIMAI, University of Modena Reggio-Emilia, Modena, Italy. ${ }^{5}$ Respiratory Rehabilitation Dept, Istituti Clinici Scientifici Maugeri IRCCS, Pavia, Italy. 'Dept of Critical Care, University Hospital Leuven, Leuven, Belgium. ${ }^{7}$ Dept of Rehabilitation Sciences, KU Leuven, Leuven, Belgium.

Correspondence: Massimiliano Polastri, Medical Dept of Continuity Care and Disability, Physical Medicine and Rehabilitation, St Orsola University Hospital, Via G. Massarenti 9, Bologna 40138, Italy. E-mail: gbptap1la gmail.com

@ERSpublications

Considering the expected high burden of respiratory, physical and psychological impairment following the acute phase of COVID-19, a huge number of patients should be referred early to a rehabilitation programme https://bit.ly/3d0s0hu

Cite this article as: Polastri M, Nava S, Clini E, et al. COVID-19 and pulmonary rehabilitation: preparing for phase three. Eur Respir J 2020; 55: 2001822 [https://doi.org/10.1183/13993003.01822-2020].

As of 15 May 2020, 4405680 coronavirus 2019 (COVID-19) cases have been reported worldwide [1]. Although figures are increasing, it seems the virus aggression is lowering, significantly reducing the pressure on the intensive care unit (ICU) beds. At the time of writing, the lockdown is going through a new phase of remodelling, and the National Authorities are testing the possibility of resuming economic activities. From the general population point of view, this is an encouraging aspect but, all those professionals involved in the pathway of care are aware of the importance this phase has on preventing the spread of the infection.

Patients who have successfully recovered from the acute COVID-19 pneumonia will require health support to define and quantify the consequences of the disease. The follow-up is currently the new challenge as it was in the beginning for ICUs. Indeed, it is not clear if COVID-19 will leave permanent lung and/or physical damage and, if so, to what extent. Alterations of lung tissue such as ground-glass opacities, consolidation, vascular thickening, bronchiectasis, pleural effusion, crazy paving pattern and irregular solid nodules [2], may progress in over $80 \%$ of patients [3]. Persisting limitations in respiratory function and gas exchange will likely be more pronounced in the subgroup of ICU survivors. In addition, as in non-COVID-19 related acute respiratory distress syndrome (ARDS) [4], we can anticipate a high incidence of ICU acquired weakness that is associated with poor short- as well as long-term outcomes [5]. It has been found that cognitive impairment in ARDS survivors ranges from $70 \%$ to $100 \%$ at hospital discharge and $20 \%$ at 5 years, while mood deterioration including depression and post-traumatic stress disorder were also present [6]. Patients with COVID-19 seem to be prone to movement-related fatigue, similar to ARDS patients [7], even in those subjects not developing a critical illness. Therefore, the rehabilitation community is calling for action preparing for post-intensive care syndrome (PICS) in COVID-19 patients

Received: 16 May 2020 | Accepted: 19 May 2020

Copyright OERS 2020. This version is distributed under the terms of the Creative Commons Attribution NonCommercial Licence 4.0. 
[8-10]. Notwithstanding, it is as yet unclear to what extent these subjects, similar to non-COVID-19 patients, are at risk for prolonged respiratory, physical, functional and cognitive limitations [11], and thus in need for appropriate rehabilitation.

Below we will address two critical questions and provide potential answers. The first question to arise is how can we identify patients with an impaired health condition after COVID-19 and how can the follow-up be organised? This is a critical point because answering such a question would include the availability of more detailed figures. Some patients with a poor health condition, specifically those with an extended long stay in the ICU, will be discharged immediately for inpatient rehabilitation. Others will be desperate to go home after the critical period in the hospital.

Post-discharge pulmonary out-patient consultations must be prepared and allow adequate early assessment of symptoms (fatigue, anxiety, depression and dysphagia), pulmonary function and exercise performance. Based on these findings, follow-up and treatment in out-patient rehabilitation or primary care with general practitioners, physiotherapists, occupational therapists and nurses can be organised. Experiences with post-ICU follow-up clinics are reported [12], but insufficient evidence is available to determine whether ICU follow-up services are effective in identifying and addressing the unmet health needs of ICU survivors [13]. Since these patients do consult their general physician more frequently [14], it is essential to raise the awareness for PICS so that patients' ICU experiences are not merely a black box for their primary care physicians [15].

The second question is what kind of rehabilitation can be conducted? Rehabilitative activities provided in an out-patient setting should consider physical, cognitive and psychosocial outcomes. Although PICS is a well-established finding in non-COVID-19 ARDS patients, its treatment is still under development $[16,17]$. Randomised controlled trials to date have not shown significant effects of post-ICU rehabilitation and exercise interventions [18-20]. Although patient's characteristics were considered to impact on the outcome of functional exercise performance in a secondary analysis of studies by DENEHY and co-workers [21, 22], the programme content might be a more critical determinant of the lack of effectiveness. Most studies in patients after ICU discharge to enhance recovery included (home-based, mostly unsupervised) exercise training interventions [20]. These interventions were primarily self-delivered exercise supported by diaries and regular phone calls [20]. It is well known from studies in patients with COPD that home-based unsupervised exercise training is not improving exercise performance in comparison to a comprehensive supervised programme [23]. In addition, patients suffering from PICS are facing not only physical but also cognitive and psychosocial impairments. Therefore, these conditions should be targeted in a multidisciplinary programme [16], such as pulmonary rehabilitation according to its definition [24], by covering the specific needs of patients suffering from PICS. Preliminary data from China support this assumption [25].

As occurred in phase one of COVID-19, when international scientific societies and professionals released practical recommendations to be followed [26-30], in phase three their contributions will also be of substantial support to get further insights into the most profitable and shared therapeutic trajectories. To define a rehabilitation programme for post-COVID-19 patients, mirroring the algorithm of pulmonary rehabilitation for patients with chronic respiratory conditions is an evidence-based, well recognised, widely accepted available option. Considering that the phenotypes trajectories are extremely different and not always related to the ICU experiences, an accurate triage and baseline core set of assessments is necessary to prioritise and offer special programmes/settings of rehabilitation (in-hospital, out-patient, telerehabilitation, tele-coaching, home-rehabilitation, mixed form). The high number of patients involved will invite technology and new health organisational approaches to be developed. The combination of either COVID versus non-COVID chronicity needs calls for an urgent answer and a sharp point of equilibrium.

Conflict of interest: None declared.

\section{References}

1 European Centre for Disease Prevention and Control. COVID-19 situation update worldwide, as of 15 May 2020. www.ecdc.europa.eu/en/geographical-distribution-2019-ncov-cases Date last updated: 2 June 2020; date last accessed: 15 May, 2020.

2 Wu J, Pan J, Teng D, et al. Interpretation of CT signs of novel 2019 coronavirus (COVID-19) pneumonia. Eur Radiol 2020; in press [https://doi.org/10.1007/s00330-020-06915-5].

3 Pan Y, Guan H. Imaging changes in patients with 2019-nCov. Eur Radiol 2020; in press [https://doi.org/10.1007/ s00330-020-06713-z].

4 Hui DS, Joynt GM, Wong KT, et al. Impact of severe acute respiratory syndrome (SARS) on pulmonary function, functional capacity and quality of life in a cohort of survivors. Thorax 2005; 60: 401-409.

5 Herridge MS, Tansey CM, Matté A, et al. Functional disability 5 years after acute respiratory distress syndrome. N Engl J Med 2011; 364: 1293-1304. 
6 Herridge MS, Moss M, Hough CL, et al. Recovery and outcomes after the acute respiratory distress syndrome (ARDS) in patients and their family caregivers. Intensive Care Med 2016; 42: 725-738.

7 Neufeld KJ, Leoutsakos JS, Yan H, et al. Fatigue symptoms during the first year after ARDS. Chest 2020; in press [http://doi:10.1016/j.chest.2020.03.059].

8 Carda S, Invernizzi G, Bavikatte G, et al. The role of physical and rehabilitation medicine in the COVID-19 pandemic: the clinician's view. Ann Phys Rehabil Med 2020; in press [https://doi.org/10.1016/j.rehab.2020.04.001].

9 Thornton J. Covid-19: the challenge of patient rehabilitation after intensive care. BMJ 2020; 369: m1787.

10 Spruit MA, Holland AE, Singh SJ, et al. Report of an ad-hoc international task force to develop an expert-based opinion on early and short-term rehabilitative interventions (after the acute hospital setting) in COVID-19 survivors (version April 3, 2020). https://ers.app.box.com/s/npzkvigtl4w3pb0vbsth4y0fxe7ae9z9 Date last updated: 3 April 2020; date last accessed: 16 May 2020.

11 Needham DM, Davidson J, Cohen $\mathrm{H}$, et al. Improving long-term outcomes after discharge from intensive care unit: report from a stakeholders' conference. Crit Care Med 2012; 40: 502-509.

12 Schaaf M VD, Bakhshi-Raiez F, Van Der Steen M, et al. Recommendations for intensive care follow-up clinics; report from a survey and conference of Dutch intensive cares. Minerva Anestesiol 2015; 81: 135-144.

13 Schofield-Robinson OJ, Lewis SR, Smith AF, et al. Follow-up services for improving long-term outcomes in intensive care unit (ICU) survivors. Cochrane Database Syst Rev 2018; 11: CD012701.

14 van Beusekom I, Bakhshi-Raiez F, de Keizer NF, et al. Dutch ICU survivors have more consultations with general practitioners before and after ICU admission compared to a matched control group from the general population. PLoS One 2019; 14: e0217225.

15 Iwashyna TJ. Survivorship will be the defining challenge of critical care in the 21st century. Ann Intern Med 2010; 153: 204-205.

16 Brown SM, Bose S, Banner-Goodspeed V, et al. Approaches to addressing post-intensive care syndrome among intensive care unit survivors. Ann Am Thorac Soc 2019; 16: 947-956.

17 Kiekens C. Follow-up services for improving long-term outcomes in intensive care unit (ICU) survivors - a Cochrane Review summary with commentary. J Rehabil Med 2019; 51: 879-882.

18 Rosa RG, Ferreira GE, Viola TW, et al. Effects of post-ICU follow-up on subject outcomes: a systematic review and meta-analysis. J Crit Care 2019; 52: 115-125.

19 Taito S, Yamauchi K, Tsujimoto Y, et al. Does enhanced physical rehabilitation following intensive care unit discharge improve outcomes in patients who received mechanical ventilation? A systematic review and meta-analysis. BMJ Open 2019; 9: e26075.

20 Connolly B, Salisbury L, O'Neill B, et al. Exercise rehabilitation following intensive care unit discharge for recovery from critical illness. Cochrane Database Syst Rev 2015; 6: CD008632.

21 Denehy L, Skinner EH, Edbrooke L, et al. Exercise rehabilitation for patients with critical illness: a randomized controlled trial with 12 months of follow-up. Crit Care 2013; 17: R156.

22 Puthucheary ZA, Denehy L. Exercise intervention in critical illness survivors: understanding inclusion and stratification criteria. Am J Respir Crit Care Med 2015; 191: 1464-1467.

23 Ries AL, Kaplan RM, Limberg TM, et al. Effects of pulmonary rehabilitation physiologic and psychosocial outcome in patients with chronic obstructive pulmonary disease. Ann Intern Med 1995; 122: 823-832.

24 Spruit MA, Singh SJ, Garvey C, et al. An official American Thoracic Society/European Respiratory Society statement: key concepts and advances in pulmonary rehabilitation. Am J Respir Crit Care Med 2013; 188: e13-e64.

25 Liu K, Zhang W, Yang Y, et al. Respiratory rehabilitation in elderly patients with COVID-19: a randomized controlled study. Complement Ther Clin Pract 2020; 39: 101166.

26 Polastri M, Brini S, Ghetti A, et al. Recommendations from scientific/professional societies: an essential support for physiotherapy in patients with COVID-19. Int J Ther Rehabil 2020; 27: 1-3.

27 Lazzeri M, Lanza A, Bellini R, et al. Respiratory physiotherapy in patients with COVID-19 infection in acute setting: position paper of the Italian Association of Respiratory Physiotherapists (ARIR). Monaldi Arch Chest Dis 2020; 90: 1285

28 Thomas P, Baldwin C, Bissett B, et al. Physiotherapy management for COVID-19 in the acute hospital setting: clinical practice recommendations. J Physiother 2020; 66: 73-82.

29 Vitacca M, Carone M, Clini E, et al. Joint statement on the role of respiratory rehabilitation in the COVID-19 crisis: the Italian position paper. Respiration 2020; in press [https://doi.org/10.1159/000508399].

30 Waldmann C, Pittard A. FICM position statement and provisional guidance: recovery and rehabilitation for patients following the pandemic. www.ficm.ac.uk/sites/default/files/ficm_rehab_provisional_guidance.pdf Date last accessed: 16 May 2020. 